\title{
The Education \& Training and the Utilization of Multi-cultural Workforce
}

\author{
SU-WON KIM \\ Korea Research Institute for Vocational Education \& Training, Sejong-si, Korea
}

\begin{abstract}
The international movement of workers and the inflow/outflow of immigrants are increasing, the term immigrant communities which country in the world is more familiar. Also, the country that accumulated a history of immigration over decades have been promoted while continuously changing the integration policies for immigrants. The immigration into home country such as the married immigrant women, etc. is constantly increasing in South Korea that had a homogeneous culture. While, it is continued to the overseas movement of young people looking for opportunities in foreign rather than domestic. In South Korea, the multi-cultural families are increasing together with the immigration of foreign workers, the marriage immigrants, etc. in accordance with the globalization of capital and labor, and the multi-cultural society is being formed in accordance with the influx of alien culture and various religious. In this paper, it explored the trends and the future outlook for the multi-cultural workforce in these dimensions. Also, in a multi-cultural society, it suggested the implications and the future assignments for the new changes in the education \& training and the employment in order to improve the quality of life and to use as the production entities of multi-cultural workforce.
\end{abstract}

Keyword: Multi-cultural workforce, Education \& training, Utilization (Employment)

\section{Introduction}

There are the international movement of workers and the inflow/outflow of immigrants are increasing, the term immigrant communities which country in the world is more familiar. Also, the country that accumulated a history of immigration over decades have been promoted while continuously changing the integration policies for immigrants.

The immigration into home country such as the married immigrant women, etc. is constantly increasing in South Korea that had a homogeneous culture. While, it is continued to the overseas movement of young people looking for opportunities in foreign rather than domestic. "Growth without employment" phenomenon continues to intensify since 2000 , as a result, because the opportunities for domestic employment of the youth were worse.

In South Korea, the multi-cultural families are increasing together with the immigration of foreign workers, the marriage immigrants, etc. in accordance with the globalization of capital and labor, and the multi-cultural society is being formed in accordance with the influx of alien culture and various religious. ${ }^{1}$

In this paper, it explores the trends and the future outlook for the multi-cultural workforce in these

Su-Won Kim, Ph.D. in Business Administration, Korea Research Institute for Vocational Education \& Training.

${ }^{1}$ In 2050 , there is expected to be an era when the foreigner is $10 \%$, that is classified as the immigrant community (Choi, 2012). 
dimensions. Also, in a multi-cultural society, it suggests the implications and the future assignments for the new changes in the education $\&$ training and the employment in order to improve the quality of life and to use as the production entities of multi-cultural workforce.

\section{Status and Trends of the Multi-cultural Workforce}

Looking at the status of foreigners to enter and stay the country (see Table 1), since 2005, every year $50,000 \sim 100,000$ people and the width of increasing was appeared to increase. Looking at the period of stay, it appeared that the long-term stay is five times higher than the short-term stay. As the cliffs effect of domestic population is visible, this trend of increasing is expected to continue because of liberalization of the global labor market, the exchange of labor workforce, etc. with an exoteric immigration policy.

Table 1

The Increased Trend of Foreigners Between the Latest 10 Years (2004-2014) (Unit: Persons)

\begin{tabular}{|c|c|c|c|c|c|}
\hline \multirow{2}{*}{ Year } & \multirow{2}{*}{ Total } & \multicolumn{3}{|c|}{ Long-term Stay } & \multirow{2}{*}{-Short-term stay } \\
\hline & & Subtotal & Enrollment & Residence Report ${ }^{2}$ & \\
\hline 2004 & 750,873 & 750,873 & 468,875 & 22,534 & 259,464 \\
\hline 2005 & 747,467 & 747,467 & 485,144 & 25,365 & 236,958 \\
\hline 2006 & 910,149 & 910,149 & 631,219 & 29,388 & 249,542 \\
\hline 2007 & $1,066,273$ & $1,066,273$ & 765,746 & 34,516 & 266,011 \\
\hline 2008 & $1,158,866$ & $1,158,866$ & 854,007 & 41,457 & 263,402 \\
\hline 2009 & $1,168,477$ & $1,168,477$ & 870,636 & 50,251 & 247,590 \\
\hline 2010 & $1,261,415$ & $1,261,415$ & 918,917 & 83,825 & 258,673 \\
\hline 2011 & $1,395,077$ & $1,395,077$ & 982,461 & 135,020 & 277,596 \\
\hline 2012 & $1,445,103$ & $1,445,103$ & 932,983 & 187,616 & 324,504 \\
\hline 2013 & $1,576,034$ & $1,576,034$ & 985,923 & 233,269 & 356,842 \\
\hline 2014 & $1,797,618$ & $1,377,945$ & $1,091,531$ & 286,414 & 419,673 \\
\hline 2015 & $1,774,603$ & $1,383,817$ & $1,094,865$ & 288,952 & 390,786 \\
\hline
\end{tabular}

Note. Source: Statistics reports on outbound-inbound foreign policy, February 2015.

The long-term stay of foreign workers in domestic may cause the deepened phenomena of a conflict by social polarization, such as the income gap between nationals and multi-cultural workforce (including immigrants) is expanding. ${ }^{3}$ In other words, if the supply of low-skilled labor migration is increased by the inflow of foreign worker, the wages of low-skilled labor are relatively is declined, and the inequalities between nationals and multi-cultural workforce is expanded, and the social and cultural conflict can be severe due to the heterogeneity of the population structure. In addition, the conflict including antipathy for foreign workers of low-income workers, education maladjusted and anti-social empowerment of multi-cultural children, etc. may also be intensified. However, a positive view, such as the changes of social values to accommodate other foreign races and cultures, etc. is also expected to appear.

According to the 2015 Statistics "Employment survey" (see Figure 1), the foreign workers who are employed in SMEs, etc. among the foreign workforce of long-term stay in the country are 988,000 people by

\footnotetext{
${ }^{2}$ If foreigners continue to resident for more than six months in the country, they must report to the Immigration Office of the Ministry of Justice.

${ }^{3}$ In the end of May 2015, the employment rate of the domestic foreign residents is $68.3 \%$, this is $7 \%$ p higher than the national average employment rate $(60.9 \%)$. The unemployment rate of those is $4.9 \%$, this is $1 \%$ p higher than the national average unemployment rate (3.8\%). (Statistical Office, 2015, p. 6).
} 
the end of 2015, and 80,000 or 90,000 people per year are increased. They are almost correspond to the simple low-skilled workforce, ${ }^{4}$ and the distributions by industry are identified as being concentrated in manufacturing, construction, food and lodging. If it combine the illegal aliens caught not on statistics besides the illegal aliens caught on statistics $(208,778$ people in the case of 2014), it is estimated to be 100 million people.

\section{Economic Activity Status of Domestic Aliens}

\begin{tabular}{|l|l|l|l|}
\hline May, 2014 & & May, 2015 & Increase(percentage) \\
\hline 125.6 million people & Foreigners aged over 15 & 137.3 million people & $\uparrow 11.8$ million $(9.4 \%)$ \\
\hline 89.6 million people & Economically Active Population & 98.6 million people & $\uparrow 9$ million $(10.0 \%)$ \\
\hline 85.2 million people & Employed & 93.8 million people & $\uparrow 8.6$ million $(10.1 \%)$ \\
\hline 0.44 million people & Unemployed & 4.8 million people & $\uparrow 0.4$ million $(9.4 \%)$ \\
\hline 36 million people & Economically inactive population & 38.7 million people & $\uparrow 2.8$ million $(7.7 \%)$ \\
\hline
\end{tabular}

Status of Foreign Workers

(O)Foreign Workers' Status by Status of Sojourn

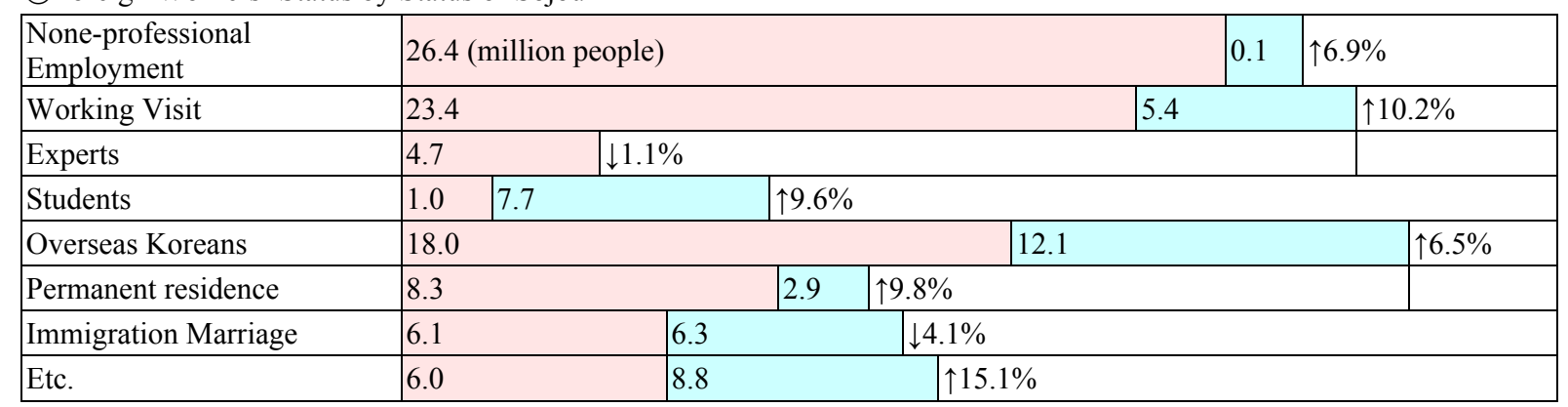

() Foreign Workers' Status by Industry

\begin{tabular}{|l|l|l|l|l|}
\hline $\begin{array}{l}\text { Mining and } \\
\text { Manufacturing }\end{array}$ & $\begin{array}{l}\text { Business, personal } \\
\text { public service }\end{array}$ & $\begin{array}{l}\text { Wholesale and retail, } \\
\text { accommodation and } \\
\text { restaurants }\end{array}$ & Construction industry & $\begin{array}{l}\text { Agriculture, Forestry } \\
\text { and Fisheries }\end{array}$ \\
\hline 43.6 million people & 18 million people & 17.9 million people & 8.6 million people & 4.1 million people \\
\hline$(\uparrow 4.3 \%)$ & $(\uparrow 26.7 \%)$ & $(\uparrow 16.5 \%)$ & $(\uparrow 0.3 \%)$ & $(\uparrow 4.1 \%)$ \\
\hline
\end{tabular}

Figure 1. The results of employment survey for foreigners (2015. 5.). Source: Statistical Office(2015. 6.)

However, according to Japan's Nomura Research Institute (2015. 12.), 49\% of Japan's labor force, 47\% of the US labor force, $35 \%$ of the UK workforce are likely to be replaced by A.I. (Artificial Intelligence) or robots Within the 10-20 years. At this time, it expects, simple low-skilled workers are mostly gone. If do so, it would be considered that most of demand for low-skilled foreign workers including immigrant workers is reduced. While, if the domestic economy is going to improve, it conduct a venture or a start-up and it are expected to increase gradually the advanced technical personnel employed by large companies. If do so, it is expected to generate a number of conflict areas on the labor supply and demand in accordance with the job sector.

\footnotetext{
${ }^{4}$ If it is the classification based on the type of visa, about $94 \%$ of the total foreign workforce is evaluated as a simple people.
} 
Currently, the multi-cultural workforce including marriage immigrants are having many difficulties from adaptation of everyday relationships to communication, child rearing, economic life (Kim, 2009). If they wish to work, there is a limit on access to the vocational (skilled) education and the job placement services because of the job-related language problems and the lack of information. For this reason, it is difficult to work where they want. And, this is leading to the second-generation immigrants and their children as well as the first generation. In addition, the gaps with natives in the side of the low income and the low enrollment of children of the multi-cultural families including immigrants are also expected to continue in the second generation of immigrants as well as the first-generation of immigrants. ${ }^{5}$

\section{New Frame and Policy Issues}

\section{Coexistence Society: Assimilation and Multi-culturalism}

It is desirable for foreign workforce to be pursued assimilation ${ }^{6}$ and multi-culturalism ${ }^{7}$ at the same time. Through the assimilation policy, the government should support the school attendance of immigrants' children, the immigrants are easier to adapt and assimilate such as non-discrimination in opportunity of jobs or education. Through multi-culturalism, the various cultures and values, language, etc. that the immigrants brought are to foster an atmosphere that is coexisted in society.

According to the international movement of workers and the outflow and influx of migrants, these foreigners are converted your recognition as their representatives of reproduction areas in domestic as well as the subject of their own growth and development. For this, it is desirable to already control the racial discrimination for domestic people as well as foreigners by enabling the education for recognition switch according to the multi-cultural society.

\section{Improvement for the Quality of Life and Utilization for the Production Subjects of Multi-cultural Workforce}

In aspects of improvement of the quality of life and of production workforce for foreign workers, it is required that not only human resource development, employment and employment maintain, and development of the related occupations but also comprehensive support of the career development, etc. needed a systematic and sustained push according to the life cycle. For this, organizations or agencies related to corporate of employers or chamber of commerce, etc. as well as government departments and affiliated public institutions should strengthen the professional network with an active participant.

For their career development, besides the education of Korean language, the basic and mandatory education of computer, etc. it is necessary to the wages assistants during the vocational training period, the operation of occupational mentoring programs, the enlargement of target for the parallel system of work and learning, strengthening education to understand the nature of immigrants, etc.

\section{Diversification for Forms of the Education and Training in Accordance With the Subjects at Various Levels}

According to the training participants increases every year and their academic background and job skills

\footnotetext{
5 According to Borjas (2005), in the United States, if the level of the first-generation immigrants generally equal to the lower of natives $20 \%$, it is not completely equal to the natives until the third-generation immigrants.

${ }^{6}$ Assimilation model is situation of the underlying policies that focus on the assimilation of immigrants to the Immigration Country. This is that the immigrants are disband its own identity while generations is passing by learning the language and the culture of the mainstream society in a short time through a help of government (Go, Kim, \& Lee, 2011).

${ }^{7}$ Multiculturalism model will acknowledge and encourage that the immigrants go to protect their cultures, and the aim of policies is co-exist rather than assimilating into mainstream society (Go, Kim, \& Lee, 2011). Since the 1970s, Canada, Australia, American society have changed the immigrants' integration way to multiculturalism model instead of assimilation model that pursued before.
} 
becomes variety among the multi-cultural workforce including immigrants, it practice in conjunction with the virtual technology utilizing ICT technology and a variety of education \& training resources such as online, universities, etc., and it is necessary to support to conduct a variety of education \& training methods that correspond to shorter lifetime and diffusion of the project-type work in technological development and social change. Furthermore, it also need the special vocational education and training, such as fostering the export specialists and the regional experts in consideration of the backgrounds or the characteristics of multi-cultural children.

In order to deploy and utilize effectively the multi-cultural workforce to the domestic labor market, it requires the information management for competency development that can be deployed and utilized at the right time and right place by recording and managing their education, career, experience, and the various learning.

\section{Changes of the Social Values to Accommodate Other Races and Cultures}

It should eliminate the social and cultural conflict, such as the income gap between the domestic people and the multi-cultural workforce, antipathy for foreign workers of domestic low-income workers, the multi-cultural children's academic maladjustment, anti-social empowerment. Also, $60 \%$ of foreign workers residing in the country must also consider the same nation as Korean-Chinese (namely, Ethnic Koreans) and the friendly relations with China. Above all, it requires a change in social values to accommodate other races and cultures in order to do this. In this aspect, it must change the social values to accommodate other races and cultures, and it needs education to cultivate a mature civic consciousness that can control the racial consciousness.

On the other hand, there is necessity to strengthen the investment of education phase at the level of the integration policy as well as the assimilation policy in order to ensure immigrants' convergence in domestic society. This should include the community education, such as ambition, social networking as well as the functions dimension, such as the vocational training, etc.

\section{Changes of the Vocational Education and Training for Enhancing the Social Adaptation and Linked to Employment}

It identify the characteristics and the interests of foreign workers including immigrants, and it should be supported to adapt to Korean culture and new jobs through considering this. Also, even as foreign immigrants with a certain level of the skills capacity, they can not get a job for their ability in many cases because of the shortages of knowledge and skill in the domestic labor market, the lack of experience, and the mistrust and the doubt on the domestic migrants. For this, it is desirable to enhance the depth counseling and perform the social adjustment education and the vocational education and training to be required. For example, it operate not only the education and training for Korean language, computer basics, professionalism, understanding of labor market, technical expertise, etc. but also the programs that form a network with employers, and it also need the special vocational training system, such as fostering the multi-cultural children as the export specialists and the regional experts of domestic enterprises. In addition, it is to conduct not only the education for understanding and promoting adapt of the korean society for immigrants but also the education for improving recognition of the multi-cultural society for the general public.

For the career development of foreign workforce including immigrants, the mentoring is required in the field of jobs for a period of time besides providing of the vocational training, and furthermore it is desirable to 
raise actively the human capital of foreign workforce by providing the opportunities of career rising and development through completion support of the regular education courses including high schools and universities. In this case, it is caused problems that can be contradiction with the domestic skilled workers, and at this time it is desirable to form a complementary relationship by varying the width of support according to job sector in making the career process.

It is needed to switch to the foundation or the flexible adaptable vocational training from center of employment in order to respond to changes of the rapid technology and market environment. For this, it should be activated the sticky network system linking the government departments, the local governments, the employers or the corporate organizations of Chamber of Commerce, etc., and the vocational training institutes to be linked vocational training to substantial employment and foundation.

\section{Development of the Talent Selection Criteria to Be Accepted Objectively and Internationally}

It need to develop common standards that the ability of the human resources can be accepted in many countries and objectively in order to be successful immigration policy. This is the same whether inflow or outflow in the foreign workforce. Also, it can be an alternative that it built and utilized the NQF (National Qualification Framework) system currently being promoted.

Enlarging alone influx of foreign workers and immigrants can not significantly improve economic growth, and it is desirable to flow into selectively the foreign workforce that can contribute to the national economy in order to achieve this effect. As one example, as most of currently incoming foreigners are simple workforce that productivity is low, they contributed to increment of the gross product but its effects are not large in gross product. Also, many conflicting phenomena is occuring in demand and supply of manpower according to the job sector. Accordingly, it is desirable to inflow into selectively the foreign workforce to be a complementary role in demand and supply of manpower. Because these foreign workforce can improve the well-being of the natives by supplying new services and goods in the country rather to be not in the position to compete with the natives.

In order to settle the labor market of the highly educated and the immigrants having a lot of experience, it is also required to seeking for schemes, such as the evaluating recognition for their existing education and career, the recognition after additional specialized training, etc. In Canada, it has given a certificate after completing additional education in higher education institutes, etc. after the procedure recognizing the existing education and career of immigrants (Go, Kim, \& Lee, 2011).

\section{Anti-discrimination in Employment and Improvement of Diversity Management for the Foreign Workers}

The mainstream of current immigrants is not the wedding immigrants and is the general immigrants, and they are becoming that country, ability level, age, etc. are more diverse than the wedding immigrant. Therefore, it is desirable to switch to the policy centering the general naturalization party from existing policy centering the wedding immigrant. In addition, it is desirable to avoid discriminatory treatment of foreign workforce including immigrants on employment, and also raise awareness and management level for diversity of foreign workforce.

It is desirable to be treated equally, such as extending the length of stay or granting the permanent residency for foreign workforce that faithfully complying with national regulations, and proving highly productivity, and paying properly taxes. 
In the impossible situation of the plant operations if there don't have the foreign workforce around the 3D industry, many small companies in the industrial field are hiring illegal immigrants. It must take measures a scheme as much as the illegal immigrants can be committed several illegal acts in the blind spot of the law. As one of this ways, it can be how to return to his country after identifying illegal immigrants within the industry, but it is desirable to seek a way to take advantage by raising skill levels through vocational training if it's necessary.

\section{Conclusion}

For the multi-cultural workforce including immigrants is desirable to seek assimilation and multi-culturalism at the same time. In addition, according to the international movement of workers and the outflow and influx of migrants, these foreigners are converted your recognition as their representatives of reproduction areas in domestic as well as the subject of their own growth and development.

Among the multi-cultural workforce including immigrants, the training participants increases every year. And according to their academic background and job skills becomes variety, it practice in conjunction with the virtual technology utilizing ICT technology and a variety of education \& training resources such as online, universities, etc., and it is necessary to support to conduct a variety of education \& training methods that correspond to shorter lifetime and diffusion of the project-type work in technological development and social change. In addition, in order to place and utilize effectively the foreign workforce in the domestic labor market, it is needed the information management that can be placed in the right place and utilized to record and manage their education, careers, experience, and a variety of learning participation.

It eliminate the social and cultural conflict with the changes of social values to accommodate the different races and cultures, it is desirable to be the stabilization of the whole society by promoting the employment stability and the social adaptability of the multi-cultural workforce. In addition, it need to utilize a selective immigration induction policy of the highly skilled immigrants with worth ability. Due to this, it can contribute to the productivity enhancement and the economic development because it increases the domestic inflow of the outstanding foreign workers in lack sector of manpower.

\section{References}

Borjas, G. J. (2005). Globalization and immigration. In M. M. Weinstein (Ed.), Globalization: What's New. Columbia University Press.

Choi, K. S. (2012). Economic impact on the inflows of foreign labor and immigration. Korea Development Research, 34(2), 95-137.

Department of Employment and Labor. (2013). Plans for the expansion of overseas employment of young people. Department of Employment and Labor.

Department of Justice. (2015). Statistics reports on outbound, inbound foreign policy. Department of Justice.

Go, H. W., Kim, S. Y., \& Lee, R. M. (2011). Korea, Taiwan, Canada's comparative analysis of the immigrants employment support policies. Korea Policy and Science Review, 15(4), 207-233.

Gwon, G. D., Gang, I. G., \& Yim, J. B. (2011). Study on the promotion of overseas employment. Korea Policy and Science Review, 15(4), 361-392.

Heo, J. J. (2014). Course of the foreign labor policy and the immigration policy. Labor Review (pp. 1-3).

International Institute for Management Development. (2015). 2015 World Talent Report. Swiss: IMD.

Jung, K. S., \& Choi, S. L. (2014). Trends and implications of the immigration policy of overseas foreign workers and the integration policy of labor market. Labor Review (pp. 32-47).

Kim, H. S. (2009). Exploratory research on the immigrant women's employment needs. Social Science Research, 26(2), 139-173. 
Korea Research Institute for Vocational Education and Training. (2015). Future prospects and new frame of the education \& training and the employment: Second Delphi survey results. Korea Research Institute for Vocational Education and Training.

Lee, S. S. (2011). Status and assignment on cultivating of the multicultural professional workforce. Multicultural Content Research, 10, 241-268.

Nomura Research Institute. (2015). Promising jobs and job specifications. Nomura Research Institute.

OECD and European Commission (2015). Policy brief on expanding networks for inclusive entrepreneurship. Luxembourg.

Statistical Office. (2015). Employment survey of foreigner. Statistical Office. 